\title{
The Ecological Ethics Framework: Finding our Way in the Ethical Labyrinth of Nature Conservation
}

\section{Commentary on "Using an ecological ethics framework to make decisions about relocating wildlife"}

\author{
Jac. A. A. Swart
}

Received: 23 January 2008/Accepted: 19 August 2008/Published online: 5 November 2008

(C) The Author(s) 2008. This article is published with open access at Springerlink.com

In their paper 'Using an ecological ethics framework to make decisions about relocating wildlife', McCoy and Berry [1] aim to modify and suggest ways to apply the ecological ethics framework proposed by Minteer and Collins [2]. The framework is meant as a tool for ecological researchers and conservationists to deal with various and sometimes conflicting ethical issues that may arise in research and conservation practices. It distinguishes four ethical domains: normative ethical theory, research ethics, animal ethics, and environmental ethics that have respectively the human community, the scientific community, nonhuman animals and the natural environment as the primary objects of moral reflection. The Minteer and Collins framework [2] implies a pluralistic and pragmatic approach to moral reasoning. It emphasizes the contextual and situational dimensions of ethical reflection in research and management situations and stresses the process of moral reasoning and deliberation by both experts and stakeholders. Minteer and Collins [2] aim to develop a wide-ranging set of case studies that can function as a database for scientists, conservationists, and students in order to deal with and learn from these cases in their own situations.

An example of such a case study is the relocation of animals for conservation ends [1]. Ethical dilemmas that can arise by moving animals include, for example, the animal's welfare versus the desired protection of such non-sentient entities as populations or ecosystems, the different moral standings of otherwise biologically similar animal groups such as wild, domesticated, endangered, and pest species, and clashes that may arise from conflicting human and animal interests.

The Minteer and Collins approach may contribute a way of dealing with such dilemmas by offering and clarifying different perspectives. However, how this should be done and whether practitioners will use it are other issues. Therefore,

\section{J. A. A. Swart (西)}

Science \& Society Group, Department of Biology, Faculty of Mathematics and Natural Sciences, University of Groningen, P. O. Box 14, 9750 AA Haren, The Netherlands

e-mail: j.a.a.swart@rug.nl 
according to McCoy and Berry [1], the implementation of this framework needs to be clarified by making the reasoning process more transparent and user-friendly and by giving more weight to individual animal ethics; namely, respecting the dignity and/or moral and legal rights of animals because it is rarely given adequate weight in current decision-making about conservation.

To achieve the first aim, the authors adopt an ethical framework proposed for the relocation of older people in the context of long-term care for the elderly [3]. This model consists of a procedure that distinguishes six dimensions or steps: (I) ethical dilemmas, (II) database and facts, (III) decision-making process, (IV) value judgments, (V) ethical principles, and (VI) action. (The model is outlined in Fig. 1 of McCoy and Berry [1]). The use of this multiple-step procedure may indeed contribute to a responsible weighting of ethical perspectives in the ecological ethics framework by identifying stakeholders, interests, values, and visions, not only in animal relocation, but also in many other conservation situations. The proposed multi-step approach to ethical conundrums will probably be more acceptable to practitioners. However, the procedure suggested by McCoy and Berry is presented in a linear way. In practice, steps taken previously may be reconsidered. For example, considering the question 'Who is to be involved?' in the decision-making process (step III) may imply re-examination of the dilemmas involved in the analysis of ethical dilemmas (step I) if new stakeholders need to be involved. Even if an action has already been performed (step VI), the consequences may force the reconsideration of the preceding steps and may be followed by an adjusted action. For these reasons, feedback loops are necessary, additional elements that merit explicit recognition and inclusion in the model.

Schneider and Sar [3] distinguish five ethical principles to be considered in their decision-making process on the relocation of older people: (I) autonomy and competency, (II) paternalism, (III) the duty to do good and avoid harm, (IV) obligations to institutions, laws, fiscal limitations and regulations, and (V) the duty to act fairly and tell the truth. In order to achieve their second aim: paying more attention to the perspectives of animal ethics in the weighting process, McCoy and Berry consider autonomy and paternalism especially with respect to non-human animals.

In my view, the application of the Schneider and Sar model to the relocation of non-human animals raises several problems. First, in considering autonomy and paternalism with respect to non-human animals, McCoy and Berry [1] interpret both terms in an evolutionary context. However, biological evolution refers to populations and species. Considering autonomy and paternalism in an evolutionary context seems to imply a group-based ethics. This conflicts with the weight McCoy and Berry want to allocate to an ethical approach centered around individual animals. Secondly the reason for choosing these two principles (i.e. autonomy and paternalism) is not clear since McCoy and Berry pay little attention to justifying their claim that adequate weighting of the dignity and/or moral and legal rights of animals is only rarely given. They write that sentiments about non-human organisms are often suppressed by other sets of principles, but do not provide much evidence for this view. While both lay people and experts may have particular or even biased ethical views on nature [4], nevertheless, making ethical choices in practical affairs 
needs more than this insight. Applying the ecological ethics framework of Minteer and Collins also requires ways of weighting and dealing with different and sometimes contrasting ethical principles and domains.

Further, the model of Schneider and Sar [3] contains a number of principles that may be relevant but also conflict with conservation and allocation practices. For example, although animals do not have competence for moral agency, one may expect that the ability of relocated non-human animals to survive in a new environment is an important factor in allocation practices. However, this may also imply the killing of less competent individuals, which conflicts with the duty to do good, to avoid harm, and to respect non-human animals. Another issue is the obligation to institutions, laws, and regulations, which may easily conflict with the interests of animals and the value assigned to them and to ecosystems. This is relevant in the example of tortoise relocation as is illustrated by McCoy and Berry [1] by the assumption that decisions on city expansion have already been made at high governmental levels. ${ }^{1}$ Finally, fairness and telling the truth should be considered in general as important principles in science-related practices such as nature conservation, but may be counterproductive from a tactical or strategic point of view. These considerations highlight the need to include a wider set of principles in the model proposed by McCoy and Berry [1].

The weighting of different, sometimes contrasting, principles and ethical domains is an important issue in a pragmatic ecological ethics. Yet, the pluralistic character of the ecological ethics framework excludes the search for unifying principles from which different rules can be derived and subsequently applied. However, this may not mean that decision-making in practical affairs is an arbitrary process. Firstly, decision makers may at least demand that in practical affairs the choice of a principle or a leading ethical domain be explicitly stated, and rationally explained and defended. Secondly, it is reasonable to require that similar cases be treated similarly. The procedures as discussed by McCoy and Berry [1] are a prerequisite for this, but guidelines, rules of thumb, criteria and so forth are also required in order to choose between competing perspectives. With the realization that contextual and situational circumstances are important in pragmatic ethics, such guidelines would indicate what kind of principles or ethical domains should have the leading role in a given situation. Thus, these guidelines do not unify but rather distribute different ethical perspectives in relation to given circumstances and the relevant knowledge or information available.

One example of this type of guideline whose purpose is to allocate principles and ethical domains (we may call them 'moral allocation principles') is the precautionary principle. It functions as a guideline in situations with much scientific uncertainty and possibly irreversible consequences resulting from human

\footnotetext{
${ }^{1}$ In step 1 of Fig. 1 in McCoy and Berry [1] an example is given of the dilemma of tortoise allocation: "Private land is being developed at the edge of cities and towns in wildlands where tortoises occur. Development is occurring piecemeal, sometimes lot-by-lot, other times with large acreages and tracts. Tortoises must be relocated to ensure well-being and survival or be killed during construction. Decisions on city expansion have already been made at high governmental levels; no more discussion is possible. There are multiple projects, some involving 1-2 tortoises, but overall, over a 30-year period, possible 500 tortoises".
} 
intervention. In such a situation, the precautionary principle tells us not to use an utilitarian weighting procedure but to abstain from the intended action. Another example is the distinction between specific and non-specific care for animals, which is based on the insight that animals depend on their environment, whether that be natural or artificial [5]. Application of this guideline means that, because domesticated animals depend on the human environment, individual (specific) caretaking should be in line with individual animal ethics. On the other hand, for wild animals that depend entirely on the natural environment, appropriate care requires attention to the wild environment, a notion that fits better with an ecocentric perspective. The latter type of care is called non-specific because it is meant for the animal as a species but is not adjusted to the specific needs and characteristics of the individual animal. However, intermediate situations are also possible and may bridge contrasting ethical positions as is shown by the Dutch experiences with the introduction of domesticated and semi-domesticated ungulates in newly created natural areas [6].

In conclusion, the ecological ethics framework proposed by Minteer and Collins [2] should not only be informed by and reflect procedural models such as the one proposed by McCoy and Berry [1], but also recognize 'moral allocation principles'. These may indeed assist in guiding policy makers, conservationists, and wildlife managers through the ethical labyrinth of practical affairs, though it should be noted that such 'moral allocation principles' should not be applied uncritically.

Open Access This article is distributed under the terms of the Creative Commons Attribution Noncommercial License which permits any noncommercial use, distribution, and reproduction in any medium, provided the original author(s) and source are credited.

\section{References}

1. McCoy, E. D., \& Berry, K. (2008). Using an ecological ethics framework to make decisions about relocating wildlife. Science and Engineering Ethics, 14(4).

2. Minteer, B. A., \& Collins, J. P. (2005). Ecological ethics: Building a new tool kit for ecologists and biodiversity managers. Conservation Biology, 19(6), 1803-1812.

3. Schneider, R. L., \& Sar, B. K. (1998). The relocation and transfer of older persons: When decisionmaking combines with ethics. Journal of Gerontological Social Work, 30, 101-115.

4. Swart, J. A. A., van der Windt, H. J., \& Keulartz, J. (2001). Valuation of nature in conservation and restoration. Restoration Ecology, 9(2), 230-238.

5. Swart, J. A. A. (2005). Care for the wild. Dealing with a pluralistic practice. Environmental values, 14(2), 251-263.

6. ICMO. (2005). Reconciling nature and human interest. Advice of the International Committee on the Management of large herbivores in the Oostvaardersplassen (IMCO). Wageningen UR: Den Haag/ Wageningen. 